L. S. B. Leakey, owing to his special knowledge of the Kikuyu and their language, has devoted much time to duties connected with the Mau Mau disturbances. The year also witnessed the official opening of the new wing by which the exhibition area in the Museum is more than doubled. The extension includes some specially designed screens with paintings of botanical subjects arranged in taxonomic order; habitat groups of coral reef and freshwater and marine fish; a large-scale relief map of the East African Territories; illustrations to explain volcanic formations, rift valleys and river meanders; minerals; Miocene and Pleistocene faunas; and the Hall of Man. A large amount of routine museum work has also been carried out in spite of the extra pressure connected with the new wing.

\section{Growth of Wounded Etiolated Avena Seedlings}

$B y$ using the infra-red image-converter viewing apparatus, C. L. Mer (Ann. Bot., N.S., 18, 157 ; 1954) has studied the effects of accurately placed localized wounds on the growth of etiolated Avena seedlings. It was essential to manipulate and wound the plantlings in complete darkness ; the method by which this was achieved is fully described. A hypodermic needle was used for the actual wounding operation. It is shown that the brief exposure to infra-red radiation does not affect the subsequent growth of the plants in darkness. The greatest effect on mesocotyl growth occurs when the node is wounded. A superficial wound in this region reduces growth by 22 per cent; a further reduction of 10 per cent takes place when the vascular system is interrupted. The growth of the coleoptile is also reduced when the node is wounded; the greater part of the reduction is due to the interruption of the vascular bundles. Wounding the plumule also reduces the growth of the seedlings; but the data are considered to $b e$ too meagre to warrant drawing firm conclusions. The results indicate that the node is the centre controlling mesocotyl growth.

\section{College of Aeronautics: Awards}

THE award of the English Electric Research Fellowship in Aeronautics for the academic year 1954-55 has been made to Mr. M. E. Filby, of 6 Hillview Avenue, Brockworth, Gloucester. Mr. Filby is a former student of Crypt Grammar School, Gloucester, and of Lincoln College, Oxford, where he obtained an honours degree in physics. $\mathrm{He}$ is at present a member of the staff of the Research Department of Gloster Aircraft Co., Ltd.

The award of the Perring Scholarship for the twoyear course which begins in October 1954 has been made to Mr. G. E. Smith, of 12 Grenoble Gardens, Palmers Green, London, N.13. Mr. Smith was educated at Glendale Grammar School, London, and graduated at the Imperial College of Science and Technology, where he obtained a first-class honours degree in civil engineering.

\section{Pan-African Congress on Prehistory}

THe third meeting of the Pan-African Congress on Prehistory will be held in Livingstone, Northern Rhodesia, in July 1955, the provisional dates being July 11-16. During the course of the meeting the centenary will be celebrated of the discovery of the Victoria Falls by Dr. David Livingstone and the beginning of the systematic exploration of the interior parts of the African continent north of the Zambesi. The work of the Congress is at present divided into three sections (though additional sections may be added if deemed necessary), namely : quaternary geology, general palæontology and climatology ; human palæontology ; and prehistoric archæology. At the meeting, symposia will be held on the Kalahari Sands, their definition, age, distribution and method of formation; the dating of the Australopithecinæ; marine strand lines, their definition, altimetric and faunal correlations; the early pebble-tool cultures, their definition, dating and distribution; and the importance and application of the carbon-14 method of dating to African prehistoric cultures. It is also proposed to hold discussions on terminology, research programmes in prehistory and allied subjects in the various African territories, the control of excavations and the care and protection of sites, and the preparation of resolutions on these subjects. A number of excursions have been arranged both to sites of prehistoric remains and to the Victoria Falls, game reserves and other places of natural beauty or general interest. The organizing secretary for the meeting at Livingstone is Dr. J. D. Clark, curator of the RhodesLivingstone Museum. All correspondence should be directed to the Organizing Secretary, Third PanAfrican Congress on Prehistory, Rhodes-Livingstone Museum, P.O. Box 124, Livingstone, Northern Rhodesia.

\section{International Association of Applied Psychology}

THE next Congress of the International Association of Applied Psychology will be held during July 18-23, 1955 , in London, plenary sessions being in the Beveridge Hall of the Senate House, University of London, and sectional meetings in Birkbeck College (which adjoins the Senate House). In addition to the opening and closing sessions, four plenary sessions will be held on the following themes: the psychologist and society; the evaluation of methods in applied psychology - the problem of criteria; the relationship between research and practice ; and the assessment of attitudes and the relation of attitude to behaviour. Only invited papers, taking up about half the time, will be given at these plenary sessions, the other half being for open discussion. The rest of the Congress will be taken up by meetings at which questions relating to particular aspects of applied psychology especially educational, clinical and occupational psychology-will be discussed. Members wishing to offer a paper should send a summary of 250 words, before December 31, to the organizing secretary, Mr. Alec Rodger, at 14 Welbeck Street, London, W.1.

\section{Conference on Endocrinology}

A WHOLE-DAY conference on "Endocrinology" has been arranged by the Joint Biology Committee and will be held at the County Hall, London, on Novem. ber 13. The speakers will be Dr. A. E. Stuart Mason, of the Medical Unit, London Hospital, on "Aspects of Endoerinology: Medical Research"; Dr. H. Gardiner-Hill, senior physician at St. Thomas's Hospital, London, on "Endocrinology from the Clinical Point of View"; Dr. T. Mann, of the Molteno Institute of Biology and Parasitology, University of Cambridge, on "Aspects of Endocrinology : the Biological Approach"; and Sir Francis Knowles, senior biology master at Marlborough College, on 